\title{
The use of the urogenital papillae of male feral African sharptooth catfish (Clarias gariepinus) as indicator of exposure to estrogenic chemicals in two polluted dams in an urban nature reserve, Gauteng, South Africa
}

\author{
Taneshka Kruger $^{\mathrm{a}, *}$, Irene Barnhoorn ${ }^{\mathrm{b}}$, Johan Jansen van Vuren ${ }^{\mathrm{a}}$, Riana Bornman ${ }^{\mathrm{b}}$ \\ ${ }^{a}$ Department of Zoology, University of Johannesburg, P.O. Box 524, Auckland Park 2006, Johannesburg, South Africa \\ ${ }^{\mathrm{b}}$ Department of Urology, Faculty of Health Sciences, University of Pretoria, P.O. Box 667, Pretoria 0001, Pretoria, South Africa
}

\begin{abstract}
The African sharptooth catfish (Clarias gariepinus) is indigenous to South Africa where it is commonly found in calm waters such as lakes, streams, rivers, swamps and floodplains. The males of this gonochoristic species can be readily distinguished from females via a distinct elongated urogenital papilla with a pointed tip, located just behind the anus. This structure is an androgen controlled secondary sexual characteristic and could potentially be affected by chemicals displaying endocrine disrupting properties during development. Results of previous studies on effects on papillae of different fish species indicated that these structures could be useful as bio-indicators of exposure due to alterations in the structures. This study investigated the occurrence of abnormal morphology in urogenital papillae compared to the macroscopic and microscopic structure of the gonads of presumed male or intersex catfish sampled from the Rietvlei and Marais dams in an urban nature reserve, due to exposure to endocrine disrupting chemicals (EDCs). Macroscopic observation of the UGP, gonad examination after laparotomy and histology were done. Gonadosomatic index (GSI) and Urogenital papilla length index (UGPLI) were determined for all fish collected. Mesenteric fat analyzed for selected alkylphenols and organochlorines showed high levels of especially nonylphenol indicating long term exposure to these chemicals due to bio-accumulation. The GSI indicated that fish with intersex gonads were probably feminized males. It was concluded that use of the UGP alone, without macroscopic and microscopic analyses of the gonads, could not effectively indicate exposure to EDCs.
\end{abstract}

\section{Keywords:}

Sharptooth catfish (Clarias

gariepinus) Urogenital papilla (UGP)

Endocrine disrupting chemicals

Intersex

\section{Introduction}

A great deal of research on chemicals displaying endocrine disruptive capabilities (often referred to as endocrine disrupting chemicals or EDCs) in wildlife has mainly focused on fish. This is due to fish demonstrating a sensitivity to these endocrine disrupters; similarities between their and the endocrine system of higher vertebrates; the ease of working with fish; and the fact that wild populations in various localities have displayed obvious endocrine disruption (Pait and Nelson, 2003). Environmental estrogens also negatively affect fish and because of their estrogen-sensitive reproductive physiology, they are vital for EDCs studies (Nimrod and Benson, 1996). A number of environmentally persistent substances alter the endocrine system in wild and laboratory exposed fish (Koger et al., 2000). Particularly in fish, EDCs cause unfavorable effects on the reproductive system that lead to irregular physiological responses

\footnotetext{
* Corresponding author.

E-mail address: tkrugerza@gmail.com (T. Kruger).
}

such as the induction of vitellogenin (VTG) synthesis and has been reported to affect the sexual behavior in fish (Oshima et al., 2003).

Another gonad condition strongly associated with the presence of EDCs is intersex (Kleinkauf et al., 2004). Among the different types of teleost reproduction, gonochorism (separate sexes) is the most common (Gimeno et al., 1998). Intersex is a pathological condition (Leusch et al., 2006), characterized by the simultaneous presence of both female and male gonadal features (ovarian and testicular tissue) in the same gonad of a single gonochoristic individual (Ishibashi et al., 2006; Milnes et al., 2006). According to (Segner et al., 2003), the occurrence of intersex or a shift of the gonadal sex ratio (ratio of ovaries and testes) has been described in some fish species after prolonged estrogen exposure. Fish can be feminized after estrogen exposure, or masculinized after androgen exposure (Hurley et al., 2004). The former is usually associated with the occurrence of oocytes in the testes (Kleinkauf et al., 2004) whilst the latter can present itself as spermatocytes in the ovaries (Jackson et al., 2006). These occur-rences can vary in appearance. The combination of female and male gonadal tissue may range from large sections of ovary and testis tissue 
within a single gonad referred to as focal intersex, to small amount of cells of one sex scattered throughout an intact gonad of the opposite sex referred to as multifocal intersex (Nolan et al., 2001; Devlin and Nagahama, 2002). Intersex is thought to occur at irregular intervals, either as result of a specific endocrine state or genetic foundation and is considered to be an accidental phenomenon (Gimeno et al., 1998). Intersex in wild fish is generally reported as the result of feminization (Hahlbeck et al., 2004). Whether EDC exposure results in intersex or more subtle changes (e.g. delayed maturation) depends on the duration (Yokota et al., 2001) and the precise timing of exposure (Milnes et al., 2006).

Concern over the effects of endocrine disrupters has led to the development of methods to monitor the presence of these substances, particularly in aquatic environments (Canapa et al., 2002). A variety of estrogenic substances is present in water systems and assessment of these substances through instrumental study is costly and requires effort at times (Iwasaki et al., 2004). Biomarkers can be used to show potentially significant endocrine disruption effects in fish gonads at an early stage (Depledge and Billinghurst, 1999). Regularly used biomarkers include plasma steroid concentrations, induction of VTGs or their mRNAs, gonadosomatic index, gonad histology and alteration of secondary sexual characteristics such as nuptial color or urogen-ital papilla (UGP) length or morphology (Tong et al., 2004). The UGP is a secondary sexual characteristic found in many fish species and development of this structure is under hormonal control (Brion et al., 2004).

The sharptooth catfish, Clarias gariepinus, an indigenous species to South Africa, is considered to be one of the most important tropical catfish species for aquaculture (De Graaf and Janssen, 1996). They are present in large numbers across the country where they inhabit calm waters from lakes, streams, rivers, swamps to floodplains, some of which are subjected to seasonal drying, but the presence of the accessory air breathing organs allow the catfish to survive (Skelton, 1993). C. gariepinus is a gonochoristic species (Schulz and Goos, 1999; Barnhoorn et al., 2004), and males can be distinguished externally from females by a distinct UGP located just behind the anus. The papilla is usually elongated with a pointed tip (Na-Nakorn et al., 2004). The presence or absence of this structure is an androgen-dependent secondary sexual characteristic (Cavaco et al., 2001). The hormonally controlled development and morphology of UGPs of various fish species may be influenced when exposed to EDCs (Brion et al., 2004). Only a few studies have focused specifically on effects on the UGP after EDC exposure. These include exposure studies done on Danio rerio (zebrafish) (Brion et al., 2004); Etheostoma caeruleum (rainbow darter) (Elias et al., 2007); Lythrypnus dalli (bluebanded goby) (Kirby et al., 2003); Oryzias latipes (Japanese medaka) (Yamamato and Suzuki, 1955; Parrott et al., 2003), and exposed or wild collected specimens of Pomatoschistus minutus.(sand goby) (Matthiessen et al., 2002; Kirby et al., 2003; Robinson et al., 2003; Robinson et al., 2004; Rodrigues et al., 2006). Results obtained indicated that the UGP can be a useful bioindicator of EDC exposure (Robinson et al., 2003) due to alterations in the structures.

Based on the above it was argued that the UGP alone of $C$. gariepinus sampled in the Rietvlei (RVD) and Marais dams (MD) in the Rietvlei Nature Reserve (RNR) could be used to indicate the occurrence of synthetic estrogens within the system. The water system receives effluent from domestic and industrial sources including agriculture, industries, informal settlements and municipal sewage treatment plants (Wepener et al., 2005). Endocrine disrupter related work has been conducted in the RNR system in the past. Aneck-Hahn (2002) used a standardized recombinant yeast estrogen bioassay (YES) to test for estrogenic activity in water samples from seven sites in the RNR and found five localities with estrogenic activity. Barnhoorn et al. (2004) stated that the system does contain substances that are known endocrine disrupters and could cause feminization in organisms. The first histological intersex evidence in feral C. gariepinus from both RVD and MD was observed at that time. C. gariepinus is the dominant indigenous fish species in both the RVD and MD. The work presented here included the histological evaluation of the occurrence of intersex in the gonads compared to papilla and gonad normality. The hypothesis was that the UGP is a reliable indicator of EDC exposure.

\section{Materials and Methods}

\subsection{Study area}

The RNR is one of the world's largest urban nature reserves and is located south of the City of Tshwane (Pretoria), Gauteng province, South Africa, merely $18 \mathrm{~km}$ from the City center but still within the city limits. The Rietvlei dam (RVD), the larger of the two dams, covers a surface area of 204,13ha when full. The smaller Marais dam (MD) is approximately $4 \mathrm{~km}$ upstream and covers a surface area of 19,47ha when full. The MD sustains the RVD and acts as a sedimentation dam before the water flows to the RVD (Wepener et al., 2005). The dams are connected through a wetland and a channel. The water system receives effluent from domestic and industrial sources including agriculture, industries, informal settlements and municipal sewage treat-ment plants (Wepener et al., 2005). Irrigation, tunnel and chicken farming and industrial activities in the form of brick works occur to the south of the Reserve. A landfill site is situated adjacent to the Reserve on the north-eastern side, a residential estate development to the east, and mainly to the west of the RNR there are small holdings with septic tanks for sanitation purposes (Bornman et al., 2007).

2.2. Collection of UGPs and gonadal tissue in the field

Catfish ( $n=97$ ) were collected seasonally via gillnets over a period of two years. Fish were weighed, total length was measured, and sex was confirmed as being either male or intersex by evaluating the UGP (Barnhoorn et al., 2004). Fish were sacrificed by severing of the spinal column behind the hard head plate. This is a standard technique and is approved by the Ethics Committee, Faculty of Science, University of Johannesburg. After laparotomy all the visceral organs were removed and the gonads were inspected macroscopically to confirm sex of the fish as being either male or intersex. The gonads were removed, weighed and a section of each gonad was fixed for $24 \mathrm{~h}$ in Bouin's solution for histological study. Tissue fixed with Bouin's appears to stain more vividly with routine histological stains (Yasutake and Wales, 1983)

The length of the UGP was measured for the UGP Length Index (UGPLI) by using a Vernier Caliper (Tricle Brand, $150 \times 0.02 \mathrm{~mm}$ ). The UGPLI represents the papilla length as a percentage of total body length (Kirby et al., 2003). The UGP was removed with a scalpel and fixed for $72 \mathrm{~h}$ in bottles containing $10 \%$ buffered neutral formalin (BNF) for later histological study. After washing and dehydration in a series of rising concentrations of ethanol and embedding in paraffin wax, sections of $5 \mu \mathrm{m}$ were cut and stained with haematoxylin and eosin (H\&E) and made into permanent mounted slides. All slides were examined histologically with light microscopy, utilizing a range of magnifications from 20 to 100 times (Barnhoorn et al., 2004).

The gonadal somatic index (GSI) was calculated according to the equation: gonadal weight/ (body weight-gonadal weight) $\times 100$ (van Aerle et al., 2001). The GSI is a somatic index that is frequently used for assessing the health and reproductive status or maturity of fish (De Vlaming, 1981). Catfish that were reared in the aquarium at the University of Johannesburg, Johannesburg, South Africa, were used as a control for comparison. Table 1 summarizes the average length, weight, GSI and UGPLI of fish collected from MD and RVD during both surveys and that of the laboratory bred control fish.

\subsection{Condition factor}

Thebodymeasurementswereusedtocalculatethecondition factor foreach individual specimen collected from the dams and also the control $\operatorname{sh}\left(\mathrm{n}^{1 / 4} 108\right)$. The condition factor K quanti es the condition of the sh, thus referring to the overall well-being of the sh and was calculated according to the equation: weight (g) 100/total length (cm) 3(Oso et al., 2011). Fish with a K value of more than one (K41) have been fed adequately, whilst a K value below one (Ko1) indicates undernourished sh.

\subsection{Mesenteric fat collection and analysis}

Fat, if present, was removed from fish for analysis. Analyses were done at the SANAS Accredited Residue Laboratory of the Agriculture Research Commission (ARC) at Onderstepoort Veterinary Institute, Pretoria, South Africa, using standard methods RNON 057 and GCMS 008 (Bornman et al., 2007). For target chemical 
Table 1

Average ( \pm SD) length and weight, GSI and UGPLI of fish collected from MD and RVD and the laboratory bred control fish.

\begin{tabular}{llllllll}
\hline Locality & Survey & Sampled fish $(\boldsymbol{n})$ & Mean length $(\mathbf{c m})$ & Mean weight $(\mathbf{k g})$ & Mean GSI (\%) & Mean UGPLI (\%) & Condition factor (\%) \\
\hline \multirow{2}{*}{ MD } & Low Flow1 & 15 & $70.23(13.08)$ & $3.42(1.98)$ & $0.26(0.10)$ & $1.70(0.51)$ & $0.87(0.18)$ \\
& High Flow1 & 13 & $72.12(7.44)$ & $2.56(1.09)$ & $0.53(0.32)$ & $2.13(0.21)$ & $0.65(0.17)$ \\
& Low Flow2 & 12 & $76.45(11.36)$ & $4.00(2.60)$ & $0.58(0.21)$ & $2.47 .(0.29)$ & $0.80(0.19)$ \\
& High Flow2 & 12 & $71.21(9.48)$ & $2.57(1.02)$ & $0.33(0.19)$ & $2.01(0.25)$ & $0.68(0.06)$ \\
\multirow{2}{*}{ RVD } & Low Flow1 & 11 & $74.36(13.13)$ & $3.84(1.94)$ & $0.10(0.07)$ & $2.11(0.49)$ & $0.85(0.12)$ \\
& High Flow1 & 10 & $75.70(8.41)$ & $3.49(1.52)$ & $0.33(0.07)$ & $2.48(0.38)$ & $0.76(0.14)$ \\
& Low Flow2 & 12 & $62.36(8.44)$ & $2.28(1.29)$ & $0.17(0.16)$ & $2.08(0.40)$ & $0.88(0.14)$ \\
\multirow{2}{*}{ Control } & High Flow2 & 12 & $76.43(11.60)$ & $4.10(1.60)$ & $0.66(0.99)$ & $2.13(0.36)$ & $0.90(0.23)$ \\
\hline
\end{tabular}

analysis, the compounds selected were Polychlorinated biphenyls (PCBs) with PCB153 as representative, alkylphenols (APs), and organochlorine (OC) pesticides. The APs, specifically 4-tert-octylphenol (OcP) and nonylphenol ( $p$-NP), were detected via fluorescence through a high performance liquid chromatography coupled to a fluorescence detector (HPLC-FLD), at a detection limit of $0.05 \mathrm{mg} / \mathrm{kg}$. The OCs were detected via gas chromatography coupled to a quadrupole mass spectrometry detector (GC-MS) operated in negative ionization mode at a detection limit of $0.010 \mathrm{mg} / \mathrm{kg}$.

\subsection{Statistics}

The intersex data was statistically analyzed for significant variations between the two dams and also between the sampling surveys. The Microsoft Office software package Excel 2000 was used to calculate averages and standard deviations. The statistical consultation services (STATKON) at the University of Johannesburg performed the statistical analyses. Levene's test was used to test all data for homogeneity of variance prior to the statistical evaluation of the data. Statistical differences were determined using a two-way analysis of variance (ANOVA). If significant, a post hoc comparison was applied to test significance of data. Scheffe's multiple comparison test was applied for homogenous data and the Dunnett's T3 test for non-homogenous data. Pearson's correlation coefficients (two-tailed) were also applied. Differences were considered to be significant at $p<0.05$. All graphs were drawn in Excel.

\section{Results}

\subsection{Urogenital papillae versus macroscopic and microscopic gonadal features}

In general catfish collected from both dams in the RNR were easily identified as male, female or possible intersex (abnormal) based on the normal UGP, urogenital opening or the abnormal UGP respectively. Females $(n=82)$, based on the normal appearing urogenital opening, were released upon identification. Out of the 97 fish collected from both dams during both seasonal surveys, only 16 individuals $(16.49 \%)$ were identified as possible intersex based on the altered morphology of their UGPs. Seven of these individuals were collected from RVD and the remaining nine from MD. However, not all the collected fish were the gender as indicated by the external normal male UGP or abnormal papilla. Table 2 summarizes the intersex data in relation to the total number of fish collected during the entire survey timeperiod and also the breakdown of intersex features per dam.

Fish had to be "re-sexed" macroscopically after laparotomy and eventually microscopically. After fish were "re-sexed" based on macroscopic inspection of the gonads, only 16 individuals (16.49\%) showed intersex i.e. both male and female gonadal features (testicular tissue and ova) present within the gonads of a single individual. Fig. 1 shows the difficulty of identifying fish as male or intersex based on the UGP alone. Only four of these individuals were collected from RVD and the remaining 12 from MD. Clarity on the actual state of intersex of all 97 fish was achieved once the specimen gonads were studied through histol-ogy. Ten of the 16 fish $(62.50 \%)$ identified as possible intersex
Table 2

Comparison of phenotypic sexual characteristic findings externally (UGP) and internally (laparotomy and histology) of all C. gariepinus collected from both dams during both seasonal surveys.

\begin{tabular}{llllll}
\hline Locality & $\begin{array}{l}\text { Total fish } \\
\text { sampled (n) }\end{array}$ & Based on & \multicolumn{2}{l}{ Sex allocation } \\
\cline { 3 - 5 } & & & Male & Intersex & Uncertain \\
\hline \multirow{2}{*}{ MD } & 52 & UGP & $36(69.23)$ & $9(17.30)$ & $7(13.46)$ \\
& & Laparotomy & $37(71.15)$ & $12(23.08)$ & $3(5.77)$ \\
& & Histology & $34(65.38)$ & $18(34.62)$ & $0(0.00)$ \\
RVD & 45 & UGP & $35(77.78)$ & $7(15.56)$ & $3(6.67)$ \\
& & Laparotomy & $40(88.89)$ & $4(8.89)$ & $1(2.22)$ \\
& & Histology & $35(77.78)$ & $10(22.22)$ & $0(0.00)$ \\
\hline
\end{tabular}

based on the UGP or gonad morphology were eventually confirmed to be intersex after histological analysis. The remaining six fish were most likely male fish with abnormal appearing UGP and/ or gonads. Fig. 2 demonstrates how fish identified as male based on the UGP and macroscopic view of the gonads eventually was identified as intersex after histological analysis.

A total of 36 (37.11\%) fish sampled displayed one or more features of intersex out of the total number of fish sampled over the entire survey time-period. Out of the 97 fish, there were 22 $(22.68 \%)$ intersex fish from MD and $14(14.43 \%)$ from RVD. The intersex features were identified either by the external UGP, macroscopically, microscopically or a combination of these. A small percentage of fish were classified as Uncertain due to the external identifier being closer to normal male or female albeit with possible damage or abnormalities, or the gonads were in the developing stages and could not readily be identified as male or female. Ten $C$. gariepinus out of all fish sampled during both surveys were identified as uncertain based on the UGP or gonadal morphology. Three of these fish were confirmed to be male through microscopic evaluation, with the remaining seven being definite intersex fish.

\subsection{GSI and UGPLI}

The GSI was calculated for each $C$. gariepinus specimen $(n=108)$. The average GSI \pm standard deviation (SD) was then calculated for each sampling period and the laboratory bred (control) fish (Table 1). The average GSI from field collected specimens were generally lower than that of the control fish. The GSI indicated that the lowest gonad condition was observed during the first low flow period in RVD at $0.10 \pm 0.07 \%$, and the highest gonad condition was observed during the second high flow period also in RVD at $0.66 \pm 0.99 \%$. There were no significant differences $(p>0.05)$ between the GSI in the intersex fish and the males from MD and so too between the intersex and male fish from RVD. 

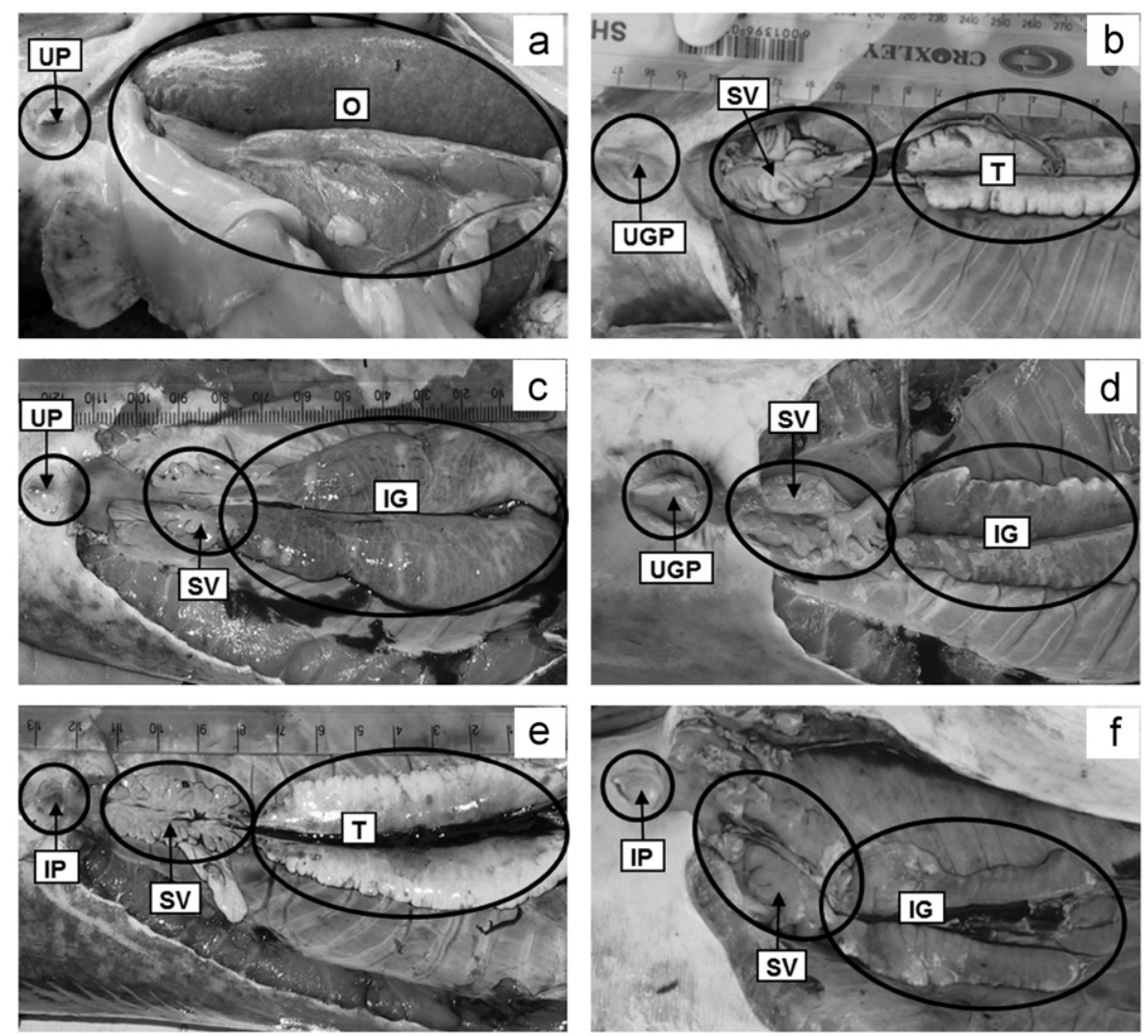

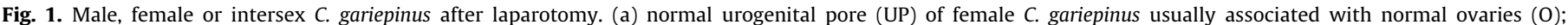

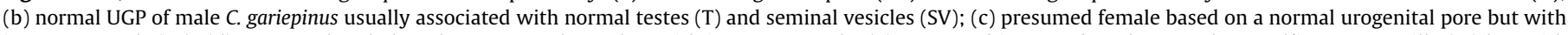

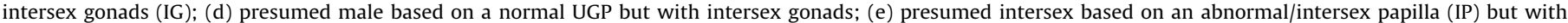
normal testes, and (f) presumed intersex based on an abnormal/intersex papilla but with intersex gonads.

The UGPLI was also calculated for each specimen. The average values $( \pm$ SD) of male and intersex fish UGPLI from MD and RVD were significantly lower than the control fish. No significant differences $(p>0.05)$ were noted between the UGPLI of male and intersex fish in MD and RVD or between the two dams. However, significant differences were noted with Scheffe's test for the UGPLI between Low flow1 and High flow1, and Low flow1 and Low flow2. Significant differences were also indicated with the Dunnett T3 test between Low flow1 and High flow1.

\subsection{Condition factor}

The condition factor average $( \pm S D)$ was calculated and is presented in Table 1 . Overall the $K$ value for all sample groups was better than the control fish $K$ value, except for both the high flow periods in MD. The condition factor determined for the sampling groups ranged from a maximum of $0.90 \pm 0.23 \%$ in the second high flow of RVD to a minimum of $0.65 \pm 0.17 \%$ in the first high flow in MD.

\subsection{Mesenteric fat}

Fat residue concentrations had to be analyzed as composite samples due to mesenteric fat not being present in all specimen collected from the RVD and MD. The levels of OCs, PCBs and APs were detected in $\mu \mathrm{g} / \mathrm{kg}$, and the average and standard deviation (average \pm SD) was determined for each survey and dam. Fish fat contained various concentrations of aldrin, lindane, $o, p^{\prime}-\mathrm{DDE}$ and $p, p^{\prime}-\mathrm{DDE}, o, p^{\prime}-\mathrm{DDD}$ and $p, p^{\prime}-\mathrm{DDD}, o, p^{\prime}-\mathrm{DDT}$ and $p, p^{\prime}-\mathrm{DDT}$ (all OCs), PCB153 and AP (OcP and $p-\mathrm{NP}$ ) residues as indicated in
Fig. 3 and Fig. 4. Detection limits were set at $10 \mu \mathrm{g} / \mathrm{kg}$. The $p, p^{\prime}-$ DDE levels in MD High Flow1 fat samples were below detec-tion limits. All DDT, DDD and DDE levels in the MD Low Flow1 samples were also below detection limits, but residues were present in remaining sample periods of the first seasonal survey. Concentrations of DDT and its metabolites were the highest in the $p, p^{\prime}$-DDE metabolite form ranging from 56.34 to $660.10 \mu \mathrm{g} / \mathrm{kg}$, indicating faster breakdown of DDT to this specific form. The lowest DDT metabolite level was that of $o, p^{\prime}$-DDE ranging from below the detection limits to $28.43 \mu \mathrm{g} / \mathrm{kg}$. Lindane levels were continually higher than that of aldrin ranging from 33.74 to $145.61 \mu \mathrm{g} / \mathrm{kg}$ and from below detected levels to $44.62 \mu \mathrm{g} / \mathrm{kg}$ respectively. The highest $\mathrm{PCB} 153$ levels were detected in fat at $67.78 \mu \mathrm{g} / \mathrm{kg}$ in fish sampled in the RVD during High Flow 1. Nonylphenol ( $p$-NP) levels ranged from 98.24 to $1440.51 \mu \mathrm{g} / \mathrm{kg}$ and were the highest residue levels for all the residues that were measured. Data for aldrin and OcP levels are not available for the second seasonal survey.

\section{Discussion}

Secondary sexual characteristics, such as male nuptial coloration or urogenital papilla development, are hormonally controlled in fish (Kirby et al., 2003; Brion et al., 2004; Robinson et al., 2004). A number of these morphological characteristics are specific only to males and include breeding tubercles (occur in many cyprinid fish), fat pad (in mature male fathead minnows), and a modified anal fin (gonopodium in the mosquitofish and guppy) (Brion et al., 2004). These all developed as the male fish becomes sexually mature 

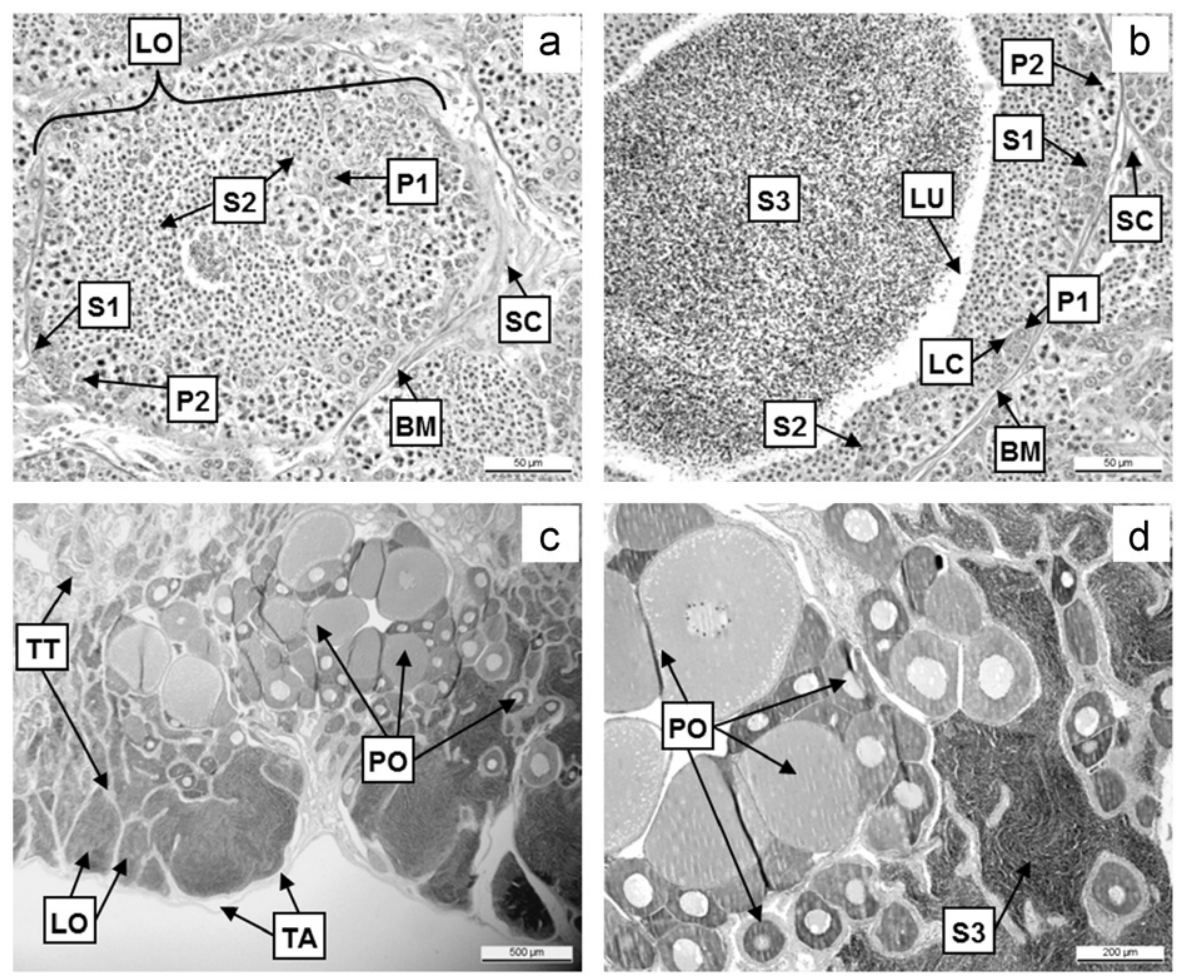

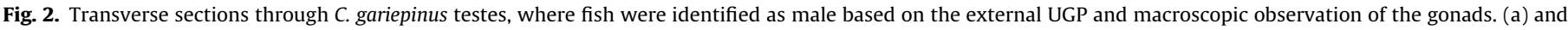

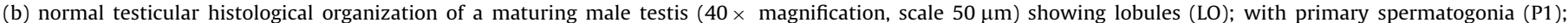

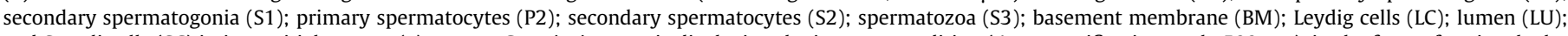

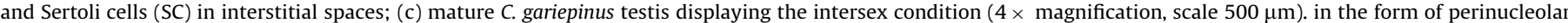

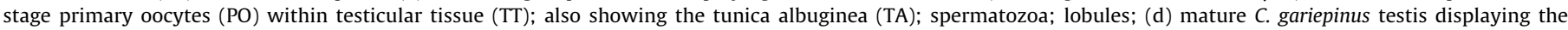
intersex condition $(10 \times$ magnification, scale $200 \mu \mathrm{m})$.

(Robinson et al., 2004). Secondary sexual characteristics of fish can be manipulated through exposure to pollutants (Robinson et al., 2003). Exposure to estrogenic chemicals induces disturbance of these structures, as shown in adult male guppy and fathead minnow (Brion et al., 2004). Fathead minnows exposed to estradiol show atrophy of fat pads and nuptial breeding tubercles in a concentration- dependent manner (Robinson et al., 2003). Studies have focused on the alterations in the UGPs of various fish species, and these structures have then also been used as indicators of EDC exposure.

C. gariepinus collected from the two dams in the RNR systems had clear evidence of abnormal appearing UGPs. It was evident from the start of sampling that most of these cases differed from each other. There was some difficulty to group the abnormalities noted in order to establish a ranking system. Sexing therefore occurred into groups of males with the normal, pear shaped UGP, females with the absence of a papilla, and intersex with varying degrees and shapes of a papilla-like structure. An easy method to identify intersex in $C$. gariepinus without having to sacrifice the animal appeared highly plausible. However, not all fish with an abnormal papilla had signs of macroscopic or microscopic intersex gonads, whilst fish with no altered UGP or macroscopic evidence of intersex in the gonads often displayed histological evidence of intersex. According to Stentiford et al. (2003), histological analysis is frequently used as an indicator of exposure to EDCs.

Another often-used indicator of EDC exposure is that of GSI (Carballo et al., 2005). One cannot measure the health status of an aquatic system directly, but the health of a system can be assessed through quantification methods that include various indices such as the GSI, hepatosomatic index (HSI) and splenosomatic index (SSI). Somatic indices such as GSI measure the overall condition of fish (Saaristo et al., 2009) within a system. The expression of indices as a percentage standardizes comparisons between organisms of different sizes, and indices have been used in various stress-related studies (Goede and Barton, 1990). Calculating the GSI is also often used to assess gonadal changes in response to environmental conditions or contaminant exposure. There is significant evidence that exposure to exogenous contaminants can lead to gonadal alterations such as morphological changes and/or decreased GSI (De Vlaming et al., 1981). The GSI values for males determined in this study were similar to those reported by Barnhoorn et al. (2004), where the GSI values for intersex catfish collected were in a closer range to the male GSI values than to females. These suggested that the intersex fish could be the result of feminization of male sharptooth catfish, similar to the observation of van Aerle et al. (2001) in Gobio gobio specimens collected from rivers in the U.K., downstream of a sewage treatment facility.

The calculating of the UGPLI appeared negligible in this field study. There was no discernible pattern in the alterations or abnormalities of the UGP of the different $C$. gariepinus specimens collected from the two dams in the RNR. The UGPLI represents the length of the UGP expressed as a percentage of the total body length of the fish. Kirby et al. (2003) used the UGPLI to determine if estrogenic exposure within U.K. water systems had any effect on the morphology of the UGP of $P$. minutus (sand gobies). No other reference could be found where the UGPLI was used to indicate EDC exposure in fish collected in the field. Robinson et al.(2003) and Robinson et al. (2004) did, however, make use of this index to indicate EDC effects in laboratory studies of $P$. minutus exposed to EE2 and a sewage effluent (containing APnEOs), 

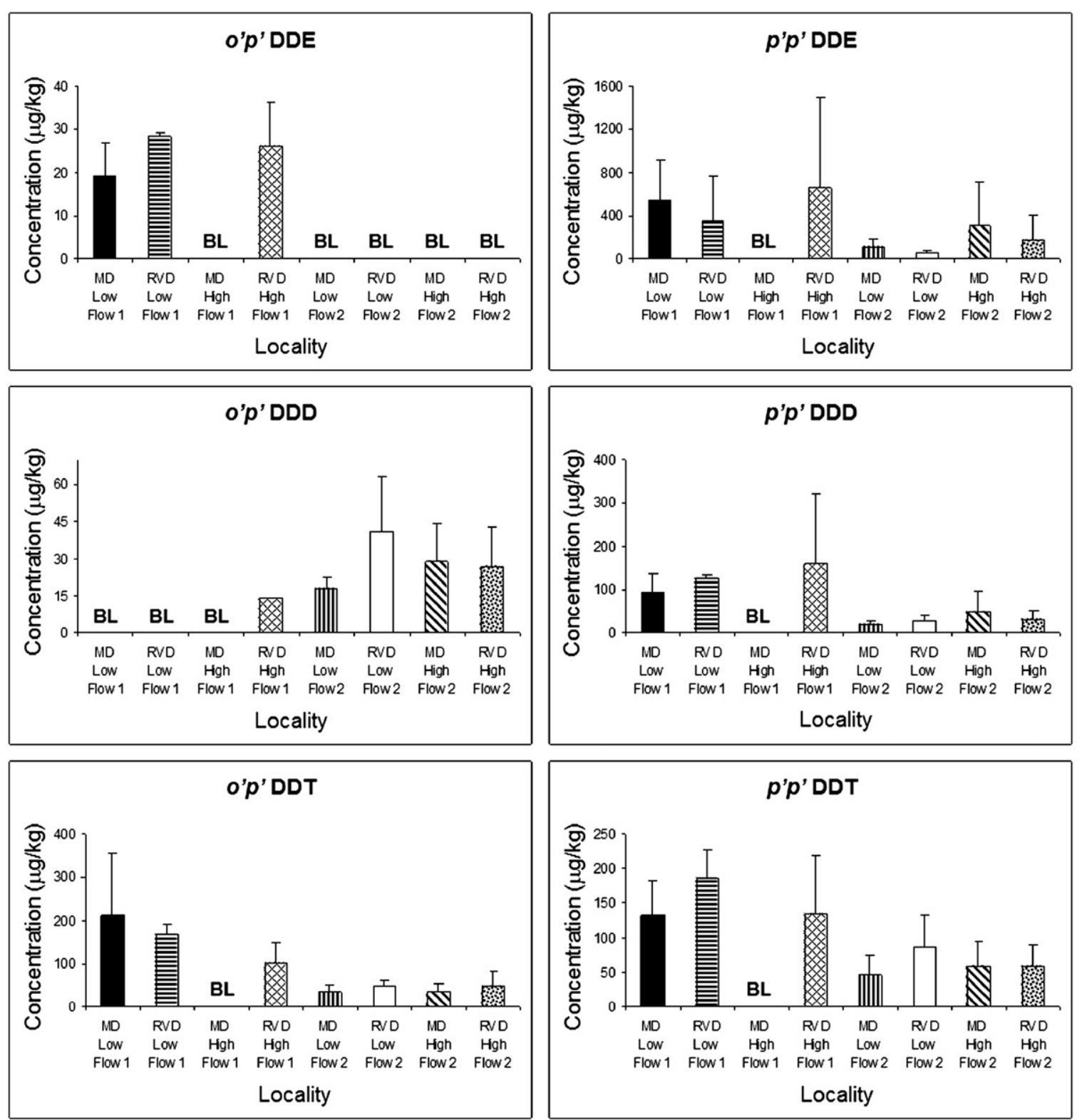

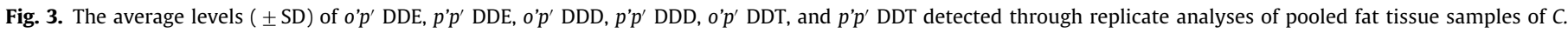

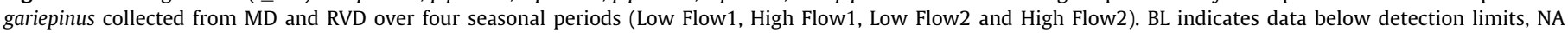
indicates data not available.

and OcP respectively. The exposure to EE2 and the sewage effluent resulted in the impairment of male UGP development and the exposure to OcP resulted in the morphological feminization of the male UGPs.

Food availability did not appear to affect the comparison between laboratory fish to the field collected specimens. The control fish had an average $K$ value that is far lower than what is determined for healthy fish. Even fish from the sampling period where the $K$ value was recorded as the maximum, the value was still not indicative of healthy fish. Not all fish had mesenteric fat, but the majority of the specimens, including the control fish, did have measurable amounts of fat. According to van Senus (1989), b o d y fat may significantly influence the condition of the fish. In spite of being reared in the laboratory with a constant food supply, the control fish were at a similar state of health as field fish.

Abnormalities noted in the UGP of $C$. gariepinus and the occurrence of high levels of chemicals possessing estrogenic activity detected in the fat of the fish are linked. The history of chemical exposure is clearly reflected by the bio-accumulated compounds in the fat tissue of fish. The altered UGPs and intersex gonads noted in collected sharptooth catfish can thus be linked to EDC exposure during the development stage, based on the mixture and levels of known EDCs detected in the mesenteric fat of the fish. Chemicals with known estrogenic activity were specifically selected for analyses. A pilot study done in the RNR by Aneck-Hahn (2002) indicated that a number of sites were positive for estrogenic activity with the $\mathrm{EC}_{50}$ - EEs ranging between 0.31 and $2.1 \mathrm{ng} / \mathrm{L}$, and this was the main motivation for analyzing only estrogenic chemicals.

The high levels of aldrin, lindane, DDT and its metabolites, and the two APs (Fig. 3 and Fig. 4) that were detected in the fat, were most likely not the cause of the intersex condition per se. Intersex is a condition that has an onset probably during embryogenesis, assuming that the fish were exposed to endocrine disrupters at that time. Studies indicate that fish early life stages are the most sensitive to toxicants (Petersen and Kristensen, 1998; Smit 

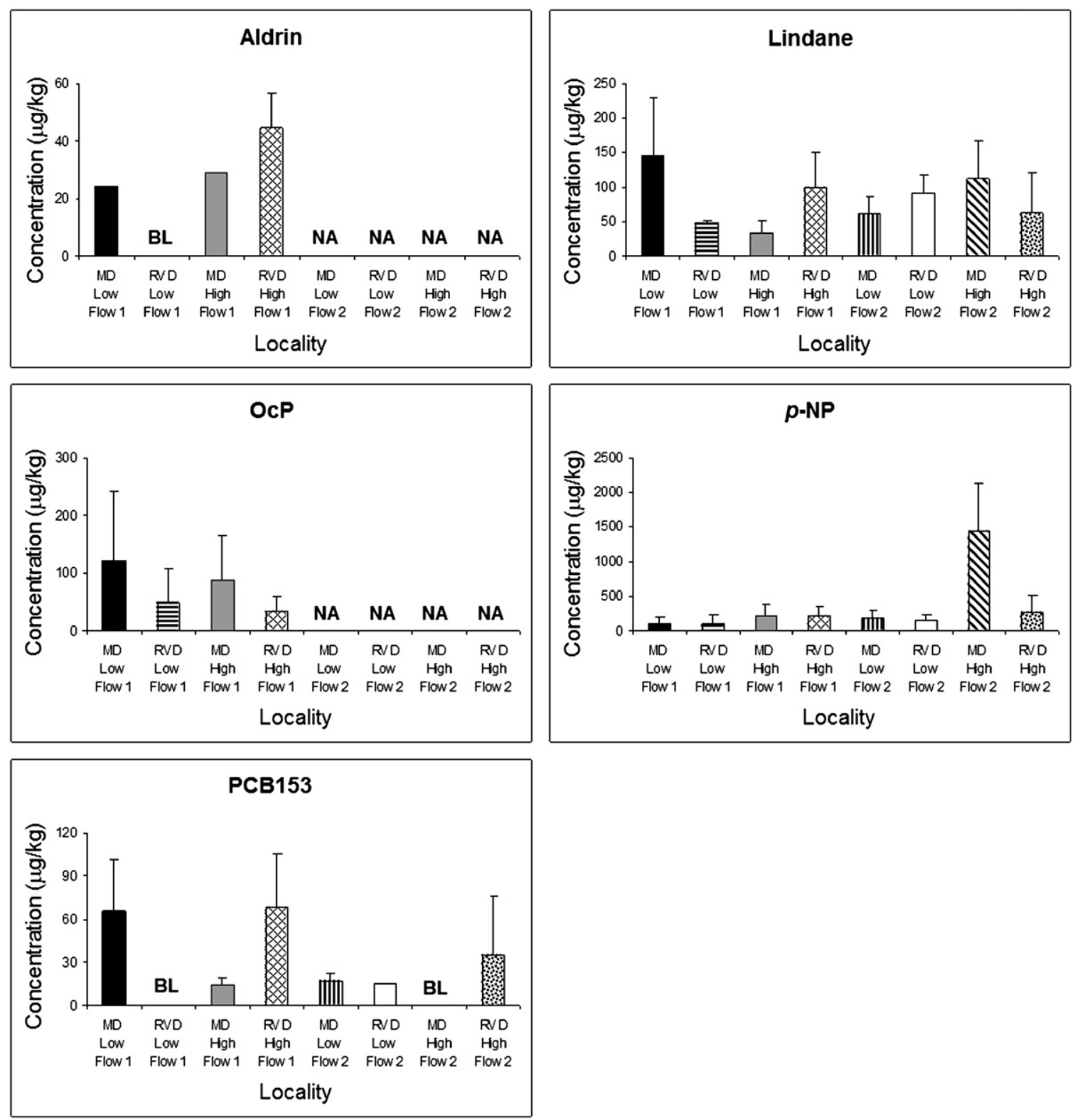

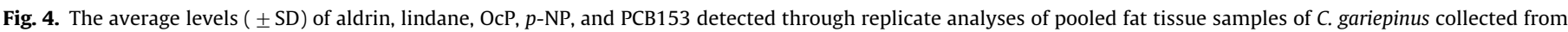

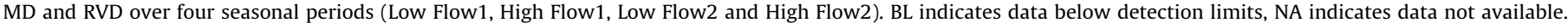

et al., 1998), and these early stages are more sensitive to estrogenic substances than older fish (Nimrod and Benson, 1998; Todorov et al., 2002). The gills and kidneys in fish embryos and larvae are poorly developed (Lee et al., 1996; Hwang and Yang, 1997; Kein̈anen et al., 2000), and the skin in these young organisms becomes the functional site of ion-regulation. Larvae therefore end up more vulnerable than adult fish, because of the larger surface area to volume ratio available for pollutant uptake. During the early life stages young organisms are also undergoing many developmental changes. Because fish are always exposed to water they can accumulate substances in their organs and tissues (i.e. fat) over time (Seymore, 1994).

The OC pesticide aldrin was commonly used for controlling soil dwelling insects such as ants and termites (ATSDR, 2010), but its use has been banned. The other detected OC pesticide lindane is produced and used as an insecticide on animals, and forest-, fruit- and vegetable crops (ATSDR, 2010). The World Health Organisation (WHO) has considered a dose of $5 \mathrm{mg} / \mathrm{kg}$ lindane per body weight to be the No Observed Effect Level (NOEL) for lindane exposure (WHO, 1991). Lindane levels detected in the fat of catfish collected during this study were all lower than this value. A mixture of environmental estrogenic substances can induce an estrogenic response even if the individual contaminants were below the concentrations to induce a response on its own. Lindane especially affects the reproductive system of organisms, and is known to interfere with the estrogen pathways in domestic ducks and rats, and induces the production of VTG in rainbow trout (Bayley et al., 1999). PCBs are known as some of the most dangerous, persistent, and toxic man-made compounds. PCB153 is one of 209 congeners that make up this class of chemical, which were produced until the 1980 s when their toxic effects were discovered. The high hydrophobicity of PCBs leads to adsorption mainly in sediments, soils, and sludge, and they are known to bio-accumulate in adipose tissue and in milk (Esté vez-Alberola and Marco, 2004).

DDT (Dichlorodiphenyltrichloroethane) persists in the environment for up to 15 years or breakdown into its main metabolites. The two most common routes of DDT metabolism are 
reductive dechlorination to DDD, and dehydrochlorination to DDE (Lean ${ }^{\circ}$ os-Castan ${ }^{2}$ da et al., 2004). The estrogenic potential of $o^{\prime} p^{\prime}$ DDT has been demonstrated by many in vitro and in vivo studies. Vitellogenin synthesis can be induced in male fish and $o$ ' $p$ ' DDT altered the sexual differentiation in Oryzias latipes during the sensitive stage of gonadal development (Okoumassoun et al., 2002). The majority of the concentrations detected in fat tissue from $C$. gariepinus specimens collected in the RNR were above the Canadian guidelines of $0.014 \mathrm{mg} / \mathrm{kg}$ diet wet weight as stipulated for the sum of all the metabolites to establish total DDT concentration (Canadian Council of Ministers of the Environment (CCME), 1999). The level of $p^{\prime} p^{\prime}$ DDE detected in the fat samples was the second highest out of all the residues detected. This specific DDT metabolite is known for its estrogenic activity, however, some studies have shown that this metabolite is a potent inhibitor of the mammalian androgen receptor, resulting in $p^{\prime} p^{\prime}$ DDE causing its feminizing effects through inhibiting masculinization (Willingham and Crews, 1999). If this is similar in fish, then the $p^{\prime} p^{\prime}$ DDE levels as detected could greatly have added to the endocrine disruption effects noted in the fish. In spite of being banned worldwide, DDT is still widely used in tropical countries for malaria vector control (Njiwa et al., 2004), and is also used in certain areas within South Africa for this exact purpose.

Alkylphenols (such as $p$-NP and OcP) are the primary degradation products of alkylphenol ethoxylates (APEs) that form in wastewater treatment facilities and the environment (Pretorius and Bornman, 2005). The high levels of nonylphenol detected in the fat of the catfish indicate that this endocrine disrupting substance played some part over time in the intersex that was observed in these fish. These metabolites mimic natural hormones by interacting with the estrogen receptor and are more toxic than the parent substances (Pretorius and Bornman, 2005). The two APs have been shown to be estrogenic in both in vitro and in vivo screening tests. Octylphenol has an estrogenic potency of 5-20 times higher than $p$-NP, but is between 100 and 10,000 times less estrogenic than E2 (Hossaini et al., 2003). Alkylphenol effects on male fish include induction of VTG, altered testis structure, and inhibition of testicular growth and sperma-togenesis (Rasmussen and Korsgaard, 2004). Seki et al., 2003 noted effects on sexual differentiation, intersex and the induction of hepatic vitellogenin on medaka exposed to $p$-NP and OcP from fertilized eggs to 60 days post hatch. The lowest-observed-effect concentrations (LOECs) of the two APs for the early life stages were 11.6 and 11.4 $\mu \mathrm{g} / \mathrm{L}$, respectively. Levels of the two APs detected in the fish fat of this study were higher than the LOECs of the early life stage medaka exposure, indicating that these two APs could have affected the young $C$. gariepinus if they were exposed during the sensitive early life stages.

The age of the $C$. gariepinus specimens collected during this study was not determined. Therefore, it is unknown for how long the fish have been exposed to the detected mixtures and concentration of estrogenic substances in the RNR system. The high levels of target chemicals measured in the fat and the probability that exposure occurred during embryogenesis, do however indicate that the RNR water system has over the years and almost certainly still does receive water from polluted sources upstream. The gross morphological changes noted in the UGPs of catfish UGP may have serious implications. In the sand goby the UGP has a role during courtship and reproduction, primarily in sperm deposition and attachment, and therefore it is possible that UGP malformations could interfere with such behavior and compromise reproductive performance (Kirby et al., 2003). The same could apply to $C$. gariepinus, which in turn could affect reproduction in the catfish with altered UGPs. This could potentially impact on the population dynamics of the species.

\section{Conclusions}

The sexes of $C$. gariepinus can usually be distinguished easily from one another by the presence of the sexual UGP. However, some of the catfish collected in the two dams of the RNR system had UGPs that displayed morphological alterations. This altered state of the UGP was thought to indicate the occurrences of the intersex condition in the catfish without having to sacrifice the fish and confirm through studying the gonads. In some cases where fish had altered UGPs, fish either displayed normal testicular histology, other displayed macroscopic intersex and the remainder displayed microscopic intersex. The UGP morphology at times did not have any alterations to indicate intersex through exposure, but the gonads showed signs of intersex at macroscopic level. The UGPs of the catfish are clearly affected by chemicals present within the system. Collected $C$. gariepinus had high levels of estrogenic endocrine disrupters bio-accumulated in their mesenteric fat. This indicates long term exposure to these chemicals, possibly from the early life stage on. A higher total incidence of intersex was noted in MD fish compared to RVD, and this was reflected in chemical mixture. In most cases the GSI values of fish with abnormal appearing UGPs were closer to that of normal male values, therefore indicating that the intersex condition was probably due to feminization of the male gonads. The UGPLI, a tool used to identify EDC exposure in sand gobies, could be considered negligible for use to indicate EDC exposure in C. gariepinus. Based on the findings in this study it may be stated that the alterations in the UGP of $C$. gariepinus could not be used as a positive indicator of EDC exposure on its own. The macroand microscopic study of the gonads must be incorporated in order to get a positive indication of the intersex condition, or to the presence of endocrine disrupter exposure.

\section{Acknowledgments}

This research formed part of a larger project funded by the Water Research Commission (WRC) of South Africa. This larger project was a collaboration between the Universities of Pretoria (Department Urology and School of Health Systems and Public Health), North-West (School of Environmental Sciences and Development, Potchefstroom Campus) and the Council for Scientific and Industrial Research (CSIR).

\section{References}

Aneck-Hahn, N.H., 2002. Screening for anti-oxidant pollutants and estrogenic activity in drinking water in poverty stricken areas of South Africa. D-Tech, Technikon Pretoria, Pretoria, South Africa.

ATSDR, 2010. Agency for Toxic Substances and Disease Registry. US Department of health and Human Services, Atlanta, Georgia. Available from: 〈http://www. atsdr.cdc.gov/toxpro2.html > (accessed in December).

Barnhoorn, I.E.J., Bornman, M.S., Pieterse, G.M., Van Vuren, J.H.J., 2004. Histological evidence of intersex in feral sharptooth catfish (Clarias gariepinus) from an estrogen-polluted water source in Gauteng South Africa. Environ. Toxicol. 19, 603-608.

Bayley, M., Nielsen, J.R., Baatrup, E., 1999. Guppy sexual behavior as an effect biomarker of estrogen mimics. Ecotoxicol. Environ. Saf. 43, 68-73.

Bornman, M.S., Van Vuren, J.H.J., Bouwman, H.H., De Jager, T.C., Genthe, B., Barnhoorn, I.E.J., 2007. Endocrine disruptive activity and the potential health risk in an Urban Nature Reserve. Report to the Water Research Committee (WRC) on the project-Application of chemical and biological assays and sentinel species for measuring EDC activity and the potential health risk. Report no. $1505 / 1 / 07$.

Brion, F., Tyler, C.R., Palazzi, X., Laillet, B., Porcher, J.M., Garric, J., Flammarion, P., 2004 . Impacts of $17 \beta$-estradiol, including environmentally relevant concentrations, on reproduction after exposure during embryo-larval-, juvenile- and adult-life stages in zebrafish (Danio rerio). Aquat. Toxicol. 68 (3), 193-217.

Canadian Council of Ministers of the Environment (CCME), 1999. Canadian tissue residue guidelines for the protection of wildlife consumers of aquatic biota: DDT (total). In: Canadian environmental quality guidelines, Canadian Council of Ministers of the Environment, Winnipeg. 
Canapa, A., B, arucca, M., Celeste, A., Olmo, E., Regoli, F., 2002. Preliminary investigations on vitellogenin m-RNA induction in some bioindicator Mediterranean fish species. Mar. Environ. Res. 54 (3-5), 673-677.

Carballo, M., Aguayo, S., De la Torre, A., Munos, M.J., 2005. Plasma vitellogenin levels and gonadal morphology of wild carp (Cyprinus carpio L.) in a receiving rivers downstream of Sewage Treatment Plants. Sci. Total. Environ. 341, 71-79.

Cavaco, J.E.B., Van Baal, J., Van Dijk, W., Hassing, G.A.M., Goos, H.J.T.H., Schulz, R.W., 2001. Steroid hormones stimulate gonadotrophs in juvenile male African catfish (Clarias gariepinus). Biol. Reprod. 64, 1358-1365.

De Graaf, G.J., Janssen, J.A.L., 1996. Artificial reproduction and pond rearing of the African catfish, Clarias gariepinus in Sub-Saharan Africa. A Handbook, FAO Fisheries Technical Paper, No 362. FAO, Rome, pp.73.

Depledge, M.H., Billinghurst, Z., 1999. Ecological significance of endocrine disruption in marine invertebrates. Mar. Pollut. Bull. 39 (1-12), 32-38.

De Vlaming, V.L., Grossman, G., Chapman, F., 1981. On the use of gonadosomatic index. Comp. Biochem. Physiol. A. 73, 31-39.

Devlin, R.H., Nagahama, Y., 2002. Sex determination and sex differentiation in fish: an overview of genetic, physiological, and environmental influences. Aquaculture 208, 191-364

Elias, E.E., Kalombo, E., Mercurio, S.D., 2007. Tamoxifen protects against $17 \alpha$-ethynylestradiol-induced liver damage and the development of urogenital papillae in the rainbow darter (Etheostoma caeruleum). Environ. Toxicol. Chem. 26 (9), 1879-1889.

Estévez-Alberola, M-C., Marco, M-P.M., 2004. Immunochemical determination of xenobiotics with endocrine disrupting effects. Anal. Bioanal. Chem. 378, 563-575.

Gimeno, S., Komen, H., Jobling, S., Sumpter, J., Bowmer, T., 1998. Demasculinisation of sexually mature male common carp, Cyprinus carpio, exposed to 4-tertpentylphenol during spermatogenesis. Aquat. Toxicol. 43 (2-3), 93-109.

Goede, R.W., Barton, B.A., 1990. Organismic indices and an autopsy-based assessment as indicators of health and condition of fish. Am. Fish. Soc. Symp. 8, 93-108.

Hahlbeck, E., Griffiths, R., Bengtsson, B-E., 2004. The juvenile three-spined stickleback (Gasterosteus aculeatus L.) as a model organism for endocrine disruption I. Sexual differentiation. Aquat. Toxicol. 70, 287-310.

Hossaini, A., Dalgaard, M., Vinggaard, A.M., Pakarinen, P., Larsen, J-J., 2003. Male reproductive effects of octylphenol and estradiol in Fischer and Wistar rats. Reprod. Toxicol. 17, 607-615.

Hurley, M.A., Matthiessen, P., Pickering, A.D., 2004. A model for environmental sex reversal in fish. J. Theor. Biol. 227, 159-165.

Hwang, P.P., Yang, C.H., 1997. Modulation of calcium uptake in cadmium pretreated tilapia (Oreochromis mossambicus) larvae. Fish. Physiol. Biochem. $16,403-410$.

Ishibashi, H., Hirano, M., Matsumura, N., Watanabe, N., Takao, Y., Arizono, K., 2006. Reproductive effects and bioconcentration of 4-nonylphenol in medaka fish (Oryzias latipes). Chemosphere 65, 1019-1026.

Iwasaki, S., Kato, S., Takahashi, M., Kimura, T., Sakka, K., Ohmiya, K., Matsuda, T, Matsui, S., 2004. Analysis of estrogen-like compounds in the environment by high performance liquid chromatography bioassay. J. Biosci. Bioeng. 97 (3), 216-218.

Jackson, K., Hurvitz, A., Din, S.Y., Goldberg, D., Pearlson, O., Degani, G., Levavi-Sivan, B., 2006. Anatomical, hormonal and histological descriptions of captive Russian sturgeon (Acipenser gueldenstaedtii) with intersex gonads. Gen. Comp. Endocrinol. $148,359-367$.

Keinänen, M., Peuranen, S., Nikinmaa, M., Tigerstedt, C., Vuorinen, P.J., 2000. Comparison of the responses of the yolk-sac fry of pike (Esox lucius) and roach (Rutilus rutilus) to low $\mathrm{pH}$ and alimunum: sodium influx, development and activity. Aquat. Toxicol. 47, 161-179.

Kirby, M.F., Bignell, J., Brown, E., Craft, J.A., Davies, I., Dyer, R.A., Feist, S.W., Jones, G. Matthiessen, C., Robertson, F.E., Robinson, C., 2003. The presence of morphologically intermediate papilla syndrome in United Kingdom populations of sand goby (Pomatoschistus spp.): Endocrine disruption? Environ. Toxicol. Chem. 22 (2), 239-251.

Kleinkauf, A., Scott, A.P., Stewart, C., Simpson, M.G., Leah, R.T., 2004. Abnormally elevated VTG concentrations in flounder (Platichthys flesus) from the Mersey Estuary (UK) — a continuing problem. Ecotoxicol. Environ. Saf. 58 (3), 356-364

Koger, C.S., Teh, S.J., Hinton, D.E., 2000. Determining the sensitive developmental stages of intersex induction in medaka (Oryzias latipes) exposed to $17 \beta$ estradiol or testosterone. Mar. Environ. Res 50 (1-5), 201-206.

Leaños-Castañeda, O., Gold-Bouchot, G., Van der Kraak, G., Lister, A., Ceja-Moreno, V., Sima-Alvarez, R., 2004. An aromatase inhibitor and tamoxifen decrease plasma levels of $o, p^{\prime}$-DDT and its metabolites in Nile tilapia (Oreochromis niloticus). Mar. Environ. Res 58, 337-342.

Lee, H.S., Hwang, P.P., Lin, H.C., 1996. Morphological changes of integumental chloride cells to ambient cadmium during the early development of the teleost. Oreochromis mossambicus. Environ. Biol. Fish. 45, 95-102.

Leusch, F.D.L., Chapman, H.F., Kay, G.W., Gooneratne, S.R., Tremblay, L.A., 2006. Anal fin morphology and gonadal histopathology in mosquitofish (Gambusia holbrooki) exposed to treated municipal sewage effluent. Arch. Environ. Contam. Toxicol. 50, 562-574.

Matthiessen, P., Allen, Y., Bamber, S., Craft, J., Hurst, M., Hutchinson, T., Feist, S., Katsiadaki, I., Kirby, M., Robinson, C., Scott, S., Thain, J., Thomas, K., 2002. The impact of oestrogenic and androgenic contamination on marine organisms in the United Kingdom - summary of the EDMAR programme. Mar. Environ. Res. 54 (3-5), 645-649.

Milnes, M.R., Bermudez, D.S., Bryan, T.A., Edwards, T.M., Gunderson, M.P., Larkin, I.V.P., Moore, B.C., Guillette Jnr, L.J., 2006. Contaminant-induced feminization and demasculinization of nonmammalian vertebrate males in aquatic environments. Environ. Res. 100, 3-17.

Na-Nakorn, U., Rangsin, W., Boon-Ngam, J., 2004. Allotriploidy increases sterility in the hybrid between Clarias macrocephalus and Clarias gariepinus. Aquaculture 237, 73-88.

Nimrod, A.C., Benson, W.H., 1996. Estrogenic responses to xenobiotics in channel catfish (Ictalarus punctatus). Mar. Environ. Res. 42 (1-4), 155-160.

Nimrod, A.C., Benson, W.H., 1998. Reproduction and development of Japanese medaka following an early life stage exposure to xenoestrogens. Aquat. Toxicol. 44, 141-156.

Njiwa, J.R., Müller, P., Klein, R., 2004. Binary mixture of DDT and Arochlor1254: effects on sperm release by Danio rerio. Ecotoxicol. Environ. Saf. 58 (2) 211-219.

Nolan, M., Jobling, S., Brighty, G., Sumpter, J.P., Tyler, C.R., 2001. A histological description of intersexuality in the roach. J. Fish. Biol. 58, 160-176.

Okoumassoun, L-E., Averill-Bates, D., Gagne, F., Marion, M., Denizeau, F., 2002 Assessing the estrogenic potential of organochlorine pesticides in primary cultures of male rainbow trout (Oncorhynchus mykiss) hepatocytes using vitellogenin as a biomarker. Toxicology 178, 193-207.

Oshima, Y., Kang, I.J., Kobayashi, M., Nakayama, K., Imada, N., Honjo, T., 2003. Suppression of sexual behavior in male Japanese medaka (Oryzias latipes) exposed to $17 \beta$-estradiol. Chemosphere 50 (3), 429-436.

Oso, J.A., Idowu, E.O., Fagbuaro, O., Olaniran, T.S., Ayorinde, B.E., 2011. Fecundity, condition factor and gonado-somatic index of Hepsetus odoe (African pike) in a tropical reservoir, Southwest Nigeria. World J. Fish Mar. Sci. 3 (2), 112-116.

Pait, A.S., Nelson, J.O., 2003. Vitellogenesis in male Fundulus heteroclitus (killifish) induced by selected estrogenic compounds. Aquat. Toxicol. 64 (3), 331-342.

Parrott, J.L., Wood, C.S., Boutot, P., Dunn, S., 2003. Changes in growth and secondary sex characteristics of fathead minnows exposed to bleached sulfite mill effluent. Environ. Toxicol. Chem. 22 (12), 2908-2915.

Petersen, G.I., Kristensen, P., 1998. Bioaccumulation of lipophilic substances in fish early life stages. Environ. Toxicol. Chem. 17 (7), 1385-1395.

Pretorius, E., Bornman, M.S., 2005. Calcium-mediated aponecrosis plays a central role in the pathogenesis of estrogenic chemical-induced neurotoxicity. Med. Hypotheses 65, 893-904.

Rasmussen, T.H., Korsgaard, B., 2004. Estrogenic octylphenol affects seminal fluid production and its biochemical composition of eelpout (Zoarces viviparus). Comp. Biochem. Physiol. C. 139, 1-10.

Robinson, C.D., Brown, E., Craft, J.A., Davies, I.M., Moffat, C.F., Pirie, D., Robertson, F. Stagg, R.M., Struthers, S., 2003. Effects of sewage effluent and ethynyl oestradiol upon molecular markers of oestrogenic exposure, maturation and reproductive success in the sand goby (Pomatoschistus minutus, Pallas). Aquat. Toxicol. 62 (2), 119-134.

Robinson, C.D., Brown, E., Craft, J.A., Davies, I.M., Moffat, C.F., 2004. Effects of prolonged exposure to 4-tert-octylphenol on toxicity and indices of oestrogenic exposure in the sand goby (Pomatoschistus minutus, Pallas). Mar Environ. Res. 58 (1), 19-38.

Rodrigues, P., Reis-Henriques, M.A., Campos, J., Santos, M.M., 2006. Urogenital papilla feminization in male Pomatoschistus minutus from two estuaries in northwestern Iberian Peninsula. Mar. Environ. Res. 62, S258-S262.

Saaristo, M., Craft, J.A., Lehtonen, K.K., Bjork, H., Lindstrom, K., 2009. Disruption of sexual selection in sand gobies (Pomatoschistus minutus) by $17 \alpha$-ethinyl estradiol, an endocrine disruptor. Horm. Behav. 55, 530-537.

Schulz, R.W., Goos, H.J.T.H., 1999. Puberty in male fish: concepts and recent developments with special reference to the African catfish (Clarias gariepinus). Aquaculture 177, 5-12.

Segner, H., Caroll, K., Fenske, M., Janssen, C.R., Maack, G., Pascoe, D., Schäfers, C. Van den Bergh, G.F., Watts, M., Wenzel, A., 2003. Identification of endocrinedisrupting effects in aquatic vertebrates and invertebrates: report from the European IDEA project. Ecotoxicol. Environ. Saf. 54 (3), 302-314.

Seki, M., Yokota, H., Maeda, M., Tadokoro, H, Kobayashi, K., 2003. Effects of 4Nonylphenol and 4-Tert-Octylphenol on sex differentiation and vitellogenin induction in medaka (Oryzias latipes). Environ. Toxicol. Chem. 22 (7) 1507-1516.

Seymore, T., 1994. Bioaccumulation of Metals in Barbus marequensis From the Olifants River, Kruger National Park and Lethal Levels of Manganese to Juvenile Oreochromis mossambicus. M.Sc. Thesis. Rand Afrikaans University, Johannesburg, South Africa.

Skelton, P.H., 1993. Volledige gids tot die varswatervisse van Suider-Afrika Southern Publishers, Halfwayhouse, Cape Town 375pp.

Smit, L., Du Preez, H.H., Steyn, G.J., 1998. Influence of natural silt on the survival of Oreochromis mossambicus yolk sac larvae. Koedoe 41 (1), 57-62.

Stentiford, G.D., Longshaw, M., Lyons, B.P., Jones, G., Green, M., Feist, S.W., 2003. Histopathological biomarkers in estuarine fish species for the assessment of biological effects of contaminants. Mar. Environ. Res. 55 (2), 137-159.

Todorov, J.R., Elskus, A.A., Schlenk, D., Lee Ferguson, P., Brownawell, B.J., Mcelroy, A.E. 2002. Estrogenic responses of larval sunshine bass (Morone saxatilis $\times$ M. Chrysops) exposed to New York City sewage effluent. Mar. Environ. Res. 54 (3-5), 691-695.

Tong, Y., Shan, T., Poh, Y.K., Yan, T., Wang, H., Lam, S.H., Gong, Z., 2004. Molecular cloning of zebrafish and medaka vitellogenin genes and comparison of their expression in response to $17 \beta$-estradiol. Gene 328, 25-36.

van Aerle, R., Nolan, M., Jobling, S., Christiansen, L.B., Sumpter, J.P., Tyler, C.R. 2001. Sexual disruption in a second species of wild cyprinid fish (the gudgeon, Gobio gobio) in United Kingdom freshwaters. Environ. Toxicol. Chem. 20 (12), 2841-2847. 
van Senus, P., 1989. Investigations into the ecology of the larger fish species, with special reference to the numerically dominant species, Oreochromis mossambicus, Clarias gariepinus and Labeo ruddi, in the Middle Letaba Dam, Gazankulu. Ph.D. Thesis, University of the North, Pietersburg.

Wepener, V., Van Vuren, J.H.J., Chatiza, F.P., Mbizi, Z., Slabbert, L., Masola, B., 2005. Active biomonitoring in freshwater environments: Early warning signals from biomarkers in assessing biological effects of diffuse sources of pollutants. Phys. Chem. Earth. 30, 751-761.

WHO, Report, 1991. International programme on chemical safety, Health and Safety Guide-54 Lindane. WHO, Geneva, p 14.

Willingham, E., Crews, D., 1999. Sex reversal effects of environmentally relevant xenobiotic concentrations on the red-eared Slider turtle, a species with temperature-dependent sex determination. Gen. Comp. Endocrinol 113, 429-435.

Yamamato, T., Suzuki, H., 1955. The manifestation of the urogenital papillae of the medaka (Oryzias latipes) by sexhormones. Embryology 2, 133-145.

Yasutake., W.T., Wales, J.H., 1983. Microscopic anatomy of Salmonids: An atlas. Fish and Wildlife service, U.S. Department of Interior. Washington, D.C.

Yokota, H., Seki, M., Maeda, M., Oshima, Y., Tadokoro, H., Honjo, T., Kobayashi, K., 2001. Life-cycle toxicity of 4-nonylphenol to medaka (Oryzias latipes). Environ. Toxicol. Chem. 20 (11), 2552-2560. 